\title{
Cold Working Effect on Creep Strength of AISI 347 Stainless Steel
}

D. D'Angelo' ${ }^{1}$ E. Evangelista ${ }^{2}$, L. Kloc ${ }^{2}$, A. Rosen ${ }^{3}$ and S. Spigarelli ${ }^{2}$

${ }^{1}$ ENEL-CRTN, Via Rubattino 54

1-20134 Milano, Italy

2 Department of Mechanics, Università di Ancona

1-60131 Ancona, Italy

${ }^{3}$ Department of Materials Engineering, Technion

Haifa 32000, Israel

\section{CONTENTS}

ABSTRACT




\begin{abstract}
The effect of 5,10 and $15 \%$ cold working on creep strength of AISI 347 stainless steel was investigated at 650 and $700^{\circ} \mathrm{C}$, with initially applied stresses of 196, 157 and $127 \mathrm{MPa}$. The relationship between minimum creep rate, applied stress and temperature was derived from the best fitting of experimental points. The stress exponent, $\mathrm{n}$, varied from 4.0 to 5.7 , and the activation energies ranged from 450 to $496 \mathrm{~kJ} / \mathrm{mol}$. The effect of cold working on creep rates, rupture times and ductilities were also studied. At 196 and $157 \mathrm{MPa}$, the $10 \%$ cold worked samples showed the lowest values both in ductility and in creep rate, and accordingly the rupture time was the maximum. The influence of cold working levels on strength and rupture behaviour was related to ageing processes and to dynamic restoration.

Some preliminary observations were performed by TEM; no particular differences were revealed in the microstructure of the specimen crept at $650{ }^{\circ} \mathrm{C}$ under various stresses or after different prestrain.
\end{abstract}

\section{Introduction}

The need for higher working temperatures in power plants is behind the development of alloys with improved performances in corrosion and creep resistance. The stabilized stainless steels AISI 321, 347 and 348 are candidates for structural components in superheater (Sh) and reheater $(\mathrm{Rh})$ banks, owing to their high temperature stability. The construction of Rh and Sh banks imposes the bending of the tubes, introducing high levels of cold work that could condition the high temperature properties of structural materials.

In stabilized stainless steels, the creep strength is affected by the balance of $\mathrm{Nb}$ and $\mathrm{Cr}$, which at low temperatures is responsible for ageing hardening. The precipitation of fine $\mathrm{Nb}$ carbides on grain boundaries during stationary creep obstructs the grain sliding and extends the rupture time $/ 1,2 /$. In creep of $25 \mathrm{Cr}-25 \mathrm{Ni}-\mathrm{Nb}$ stabilized stainless steel, a large reduction of minimum crecp rate and ductility was attributed to high dislocation density and cavitation, respectively, produced by $25 \%$ cold work $/ 3 /$.

After ageing the AISI 347 stainless steel, $30 \%$ cold worked $(\mathrm{CW})$ specimens exhibited limited increases in microhardness, whereas more severe $\mathrm{CW}$ values produced softening due to recovery $/ 4 /$.

The aim of this research is to investigate the effect of different cold work levels on creep behaviour of the niobium stabilized stainless steel AISI 347.

\section{Materials and Experimental}

Constant temperature and constant load creep rupture experiments were done on specimens machined from tubes of the following dimensions: $51 \mathrm{~mm}$ outer diameter, $7.2 \mathrm{~mm}$ wall thickness. The composition of the alloy was as follows (wt\%): $17.3 \mathrm{Cr}, 10.4 \mathrm{Ni}, 0.048$ C, $0.52 \mathrm{Nb}$ and $<0.01 \mathrm{Ta}$.

The creep specimens were cylindrical and their gauge length was $50 \mathrm{~mm}$, with a $5 \mathrm{~mm}$ diameter. Creep tests were performed on as received as well as on predeformed specimens. The pre-straining was performed on a tensile machine at room temperature to 5,10 and $15 \%$ deformation. The creep tests were carried out at 650 and $700^{\circ} \mathrm{C}$ under stresses of 127,157 and $196 \mathrm{MPa}$. Temperatures varied within $\pm 3{ }^{\circ} \mathrm{C}$ of the test values; strain measurements were performed using LVDT (linear variable differential transformers). The linearity error in elongation measurements was $<0.2 \%$.

\section{Results}

Figs. la-Id show various creep curves obtained at different temperatures under different applied stresses; the data marks represent experimental results, while the curves were fitted by using the $\theta$ projection concept /5/ modified with the addition of the $\epsilon_{\text {cut off }}$ method $/ 6 /$.

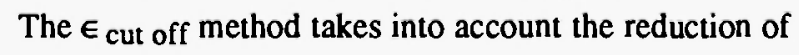
sample diameter due to cavitation and necking by erasing the last point in the fitting experimental data. The strain corresponding to $\mathrm{t}=0.8 \mathrm{t}_{\text {rupt }}$, where $\mathrm{t}_{\text {rupt }}$ is the rupture time, was arbitrarily assumed as $\epsilon_{\text {co. }}$. The last part of the creep curves is not shown in Fig. 1, owing to different tertiary behaviour typical of stainless steels in constant stress and constant load experiments $\Pi$.

The proposed equation is: 

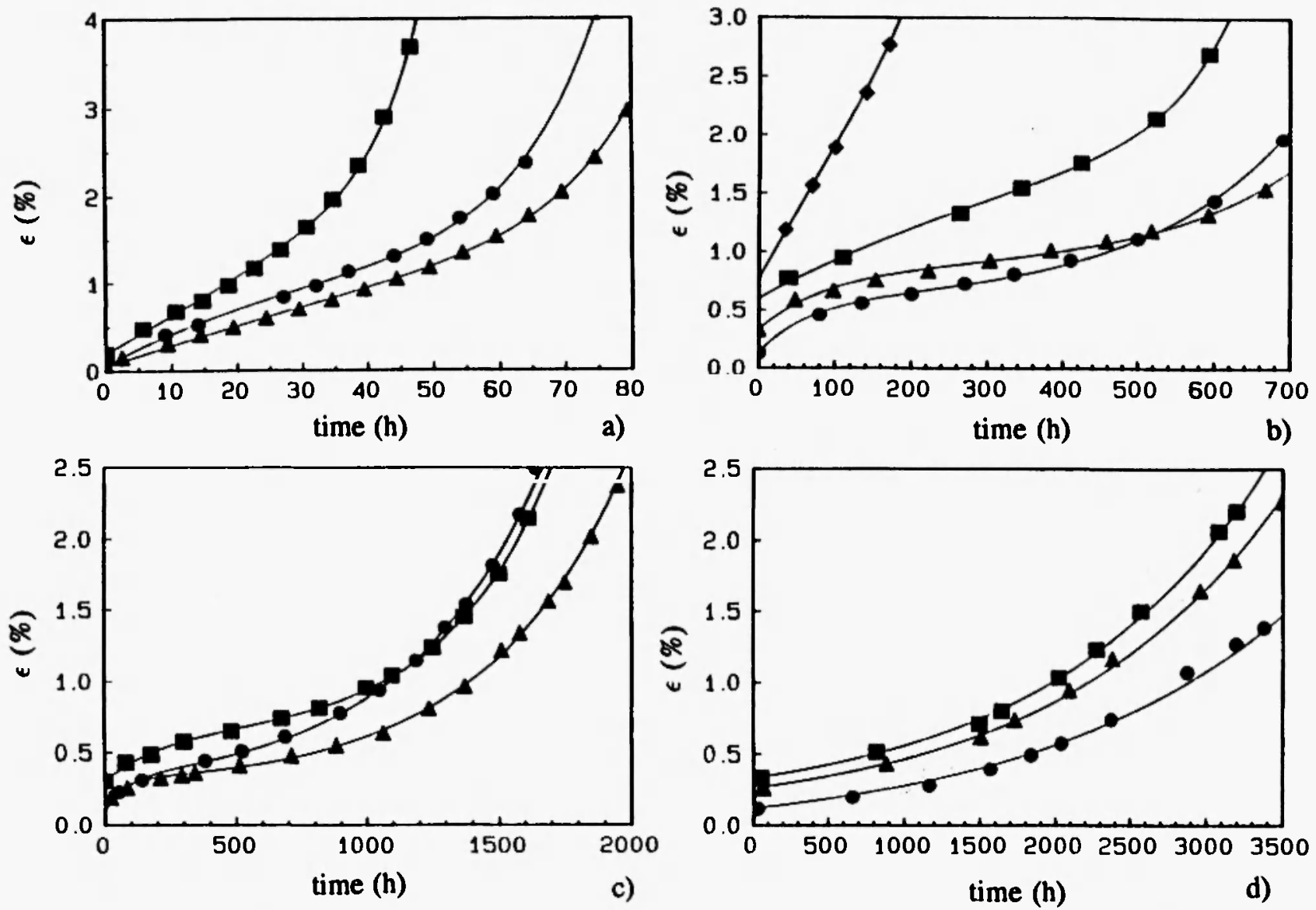

Fig. 1: Effect of cold work on creep curves at different test conditions: a) $196 \mathrm{MPa}, 700{ }^{\circ} \mathrm{C}$; b) $196 \mathrm{MPa}$, $650^{\circ} \mathrm{C}$; c) $157 \mathrm{MPa}, 650^{\circ} \mathrm{C}$; d) $127 \mathrm{MPa}, 650^{\circ} \mathrm{C}$.

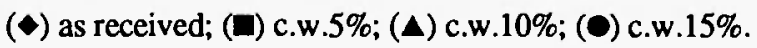

$$
\epsilon=\theta_{1}\left(1-e^{-\theta_{2} t}\right)+\theta_{3}\left(e^{\theta_{4} t}-1\right)+\epsilon_{0}
$$

where $\theta_{i}(i=1,4)$ depends on test conditions through the following equations:

$$
\begin{array}{r}
\ln \left(\Theta_{i}\right)=a_{i}+b_{i} t+c_{i} \sigma+d_{i} \sigma t \\
i=1,4
\end{array}
$$

where $T$ is the temperature and $\sigma$ is the applied stress. The minimum creep rate $\epsilon_{\mathrm{m}}$, (Fig. 2) was calculated by deriving Eq. 1 and substituting the time $\mathrm{t}_{\mathrm{m}}$, transition time from primary to tertiary stages, defined as follows:

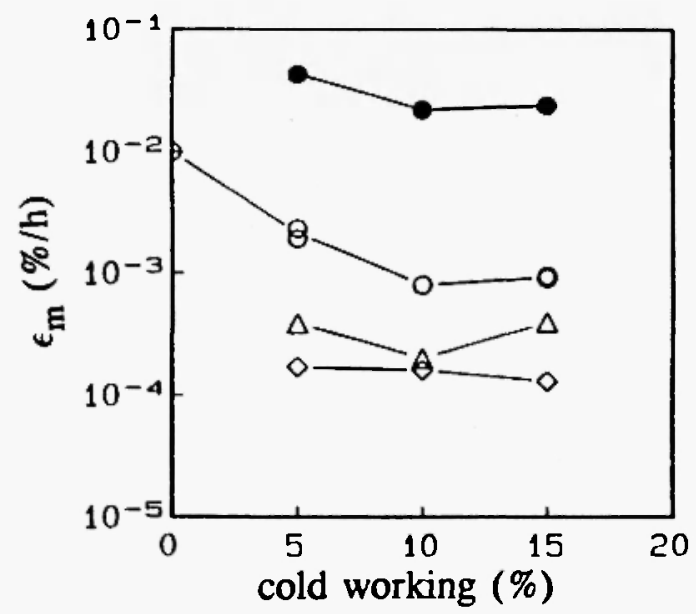

Fig. 2: Variation of MCR with the amount of cold work for different test conditions: $700{ }^{\circ} \mathrm{C}$ $196 \mathrm{MPa}(\bullet) ; 650^{\circ} \mathrm{C}-196 \mathrm{MPa}(\mathrm{O}) ; 650$ ${ }^{\circ} \mathrm{C}=157 \mathrm{MPa}(\Delta) ; 650^{\circ} \mathrm{C}-127 \mathrm{MPa}(0)$. 


$$
t_{m}=\left(\frac{1}{\theta_{2}+\theta_{4}}\right) \ln \left(\frac{\theta_{1} \theta_{2}^{2}}{\theta_{3} \theta_{4}^{2}}\right)
$$

All creep curves in Figs. la-lc are typical threestage creep curves, with relatively short primary and secondary regions. Table 1 lists the values of the minimum creep rate (MCR) and $t_{m}$ for the various creep experiments. In general, pre-straining lowers the minimum creep rate and increases creep life. The lowest MCR and longest $t_{r}$ were obtained for the $10 \%$ prestrained specimens, except for the very low load experiments. It is to be noted that $10 \%$ prestraining extends creep life by an order of magnitude compared to that of annealed specimens. The apparent activation energy for creep, $Q$, and the stress sensitivity parameter, $n$, were calculated by means of the following equation:

$$
\dot{\varepsilon}_{m}=A \sigma^{n} e^{\left(\begin{array}{l}
-O \\
R T
\end{array}\right)}
$$

where $\mathrm{A}$ is material constant and $\mathrm{R}$ has the usual meaning.

The n values at $650^{\circ} \mathrm{C}$ were $5.7,4.7$ and 4 for 5 , 10 and $15 \% \mathrm{CW}$, respectively, and the activation energy ranges from 496 to $450 \mathrm{~kJ} / \mathrm{mol}$. These results agree very well with data reported in the literature $/ 8 /$.

\section{Microstructure}

Preliminary observation performed by TEM showed a regular three-dimensional network of dislocations and a high number of fine $\mathrm{NbC}$ particles. A rather rough estimation of dislocation densities is summarized in Table 2; a tendency for dislocation density to increase with cold work level can be observed, even if no dependence on creep load occurs. The homogeneity of particle densities increases with increasing cold deformation.

Three principal types of particles were revealed in the crept speciments:

- Type 1: coarse intergranular particles (Fig. 3)

- Type 2: coarse intragranular particles having an
Table 1

Effect of c.w. and test conditions on MCR and time $t_{m}$

\begin{tabular}{||c|c|c|c|c||}
\hline $\begin{array}{c}\text { c.w. } \\
\%\end{array}$ & $\begin{array}{c}\mathrm{T} \\
{ }^{\circ} \mathrm{C}\end{array}$ & $\begin{array}{c}\sigma \\
\mathrm{MPa}\end{array}$ & $\begin{array}{c}\epsilon_{\mathrm{m}} \\
\% / \mathrm{h}\end{array}$ & $\begin{array}{c}\mathrm{t}_{\mathrm{m}} \\
\mathrm{h}\end{array}$ \\
\hline 0 & 650 & 196 & .01 & 6 \\
\hline 5 & 650 & 196 & .0019 & 270 \\
\hline 5 & 650 & 196 & .0023 & 305 \\
\hline 10 & 650 & 196 & .00078 & 289 \\
\hline 15 & 650 & 196 & .00095 & 228 \\
\hline 15 & 650 & 196 & .00091 & 203 \\
\hline 5 & 650 & 157 & .00039 & 508 \\
\hline 10 & 650 & 157 & .00020 & 312 \\
\hline 15 & 650 & 157 & .00040 & 341 \\
\hline 5 & 650 & 127 & .00017 & 111 \\
\hline 10 & 650 & 127 & .00016 & 120 \\
\hline 15 & 650 & 127 & .00013 & 93 \\
\hline 5 & 700 & 196 & .0425 & 10 \\
\hline 10 & 700 & 196 & .0216 & 27 \\
\hline 15 & 700 & 196 & .0236 & 28 \\
\hline
\end{tabular}

Table 2

Estimation of dislocation densities $\left(10^{14} \mathrm{~m}^{-2}\right)$ in specimens crept at $650{ }^{\circ} \mathrm{C}$ at various stresses after different cold work

\begin{tabular}{||c|c|c|c||}
\hline $\begin{array}{c}\text { c.w. } \\
\%\end{array}$ & $\begin{array}{c}127 \\
\mathrm{MPa}\end{array}$ & $\begin{array}{c}157 \\
\mathrm{MPa}\end{array}$ & $\begin{array}{c}196 \\
\mathrm{MPa}\end{array}$ \\
\hline 0 & - & - & 3.2 \\
\hline 5 & 3.0 & 2.5 & 3.5 \\
\hline 10 & 4.8 & - & 4.0 \\
\hline 15 & 4.8 & 3.2 & 5.6 \\
\hline
\end{tabular}




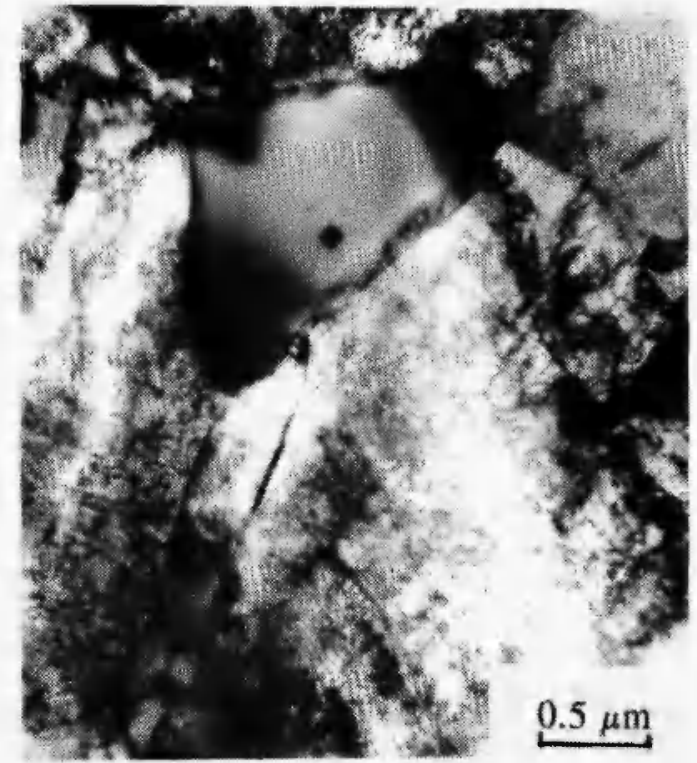

Fig. 3: Coarse intercrystalline precipitates observed by TEM in $15 \%$ c.w. specimen crept at 650 ${ }^{\circ} \mathrm{C}$ and $157 \mathrm{MPa}$.

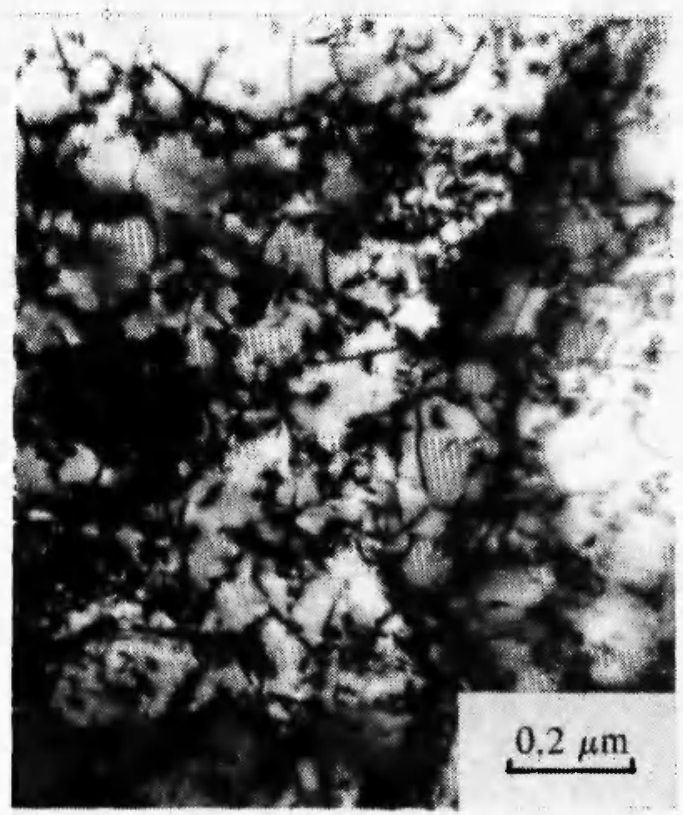

Fig. 5: Fine precipitates observed by TEM in 5\% c.w. specimen crept at $650^{\circ} \mathrm{C}$ and $127 \mathrm{MPa}$.

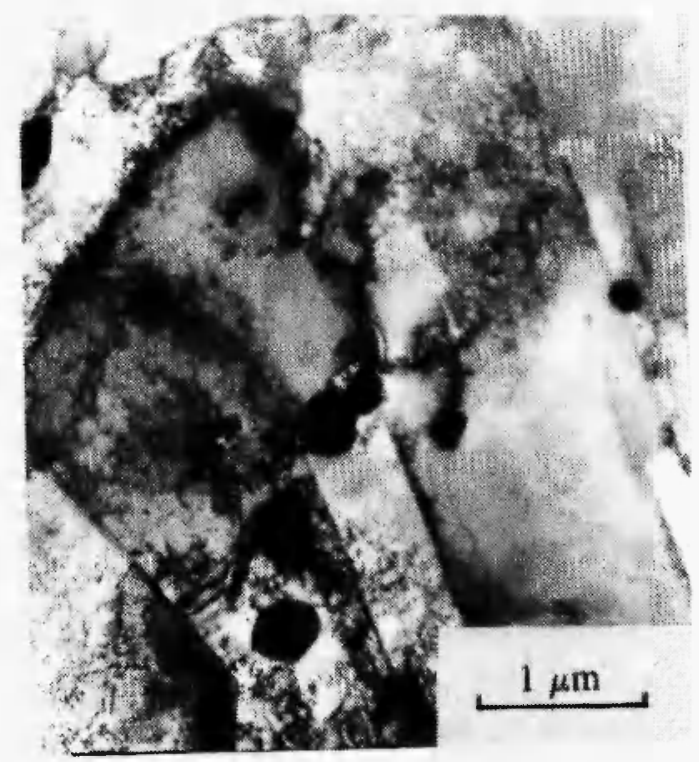

Fig. 4: Coarse equiaxial intracrystalline precipitates observed by TEM in 5\% c.w. specimen crept at $650^{\circ} \mathrm{C}$ and $127 \mathrm{MPa}$.

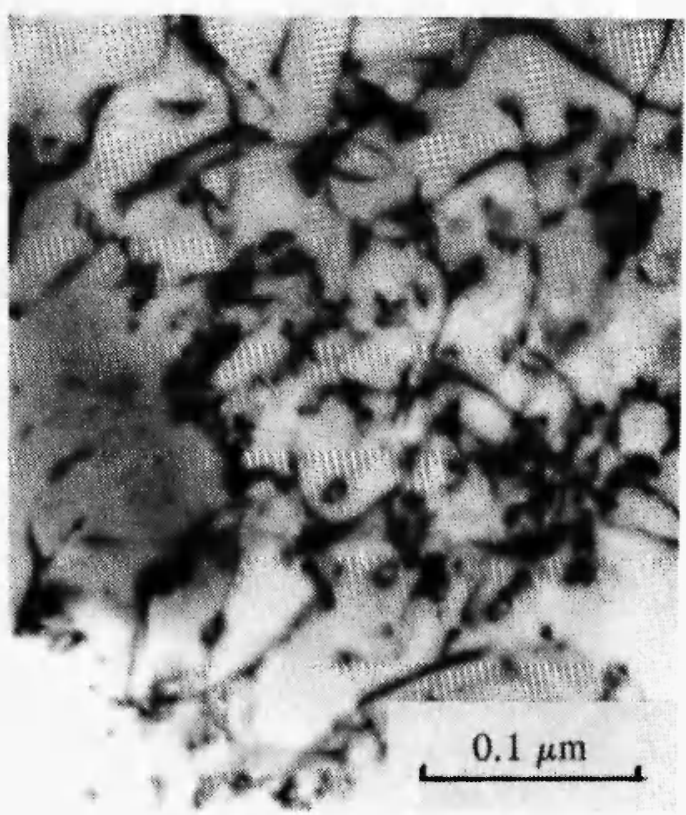

Fi. 6: Fine precipitates observed by TEM in 10\% c.w. specimen crept at $650^{\circ} \mathrm{C}$ and $196 \mathrm{MPa}$. 
equiaxial shape (Fig. 4)

- Type 3: very fine particles precipitating mainly on dislocations (Figs. 5 and 6)

While particles of types 1 and 3 are present in all specimens, type 2 particlcs occur predominantly in specimens having time to rupture longer than $500 \mathrm{~h}$.

\section{Discussion}

The fact that $\mathbf{n}$ and $\mathrm{Q}$ fit very well the reported values for stainless steels in literature indicates that the basic creep deformation mechanism in this steel is not different from that of the others $/ 8 /$. On the other hand, slight plastic deformation by pulling at room temperature has a significant influence mainly on the minimum creep rate. It is suggested that the significant improvement of creep behaviour due to cold work is to be attributed to the precipitation of niobium carbides during creep.

Fig. 7 shows the plot for the Monkman-Grant relationship. These results show that prior cold work does not produce considerable damage or cavity nucleation, and pre-straining does not introduce qualitative changes in creep deformation mechanisms, even if, according to Ahn et al. /9/, these conclusions can change drastically with the variation in testing procedures.

During creep at elevated temperatures, carbides precipitate and cause pinning of dislocations /10-12/; the pinning not only increases creep strength, but also stabilizes the dislocation network. Higher dislocation densities in pre-deformed specimens present better conditions for particle nucleation. Microstructure observations reveal a regular three-dimensional network of dislocations and a high number of particles precipitated on the dislocations. Both dislocation and particle densities increase with the increasing cold work level before creep test. On the other hand, prolonged holding at high temperatures results in carbide growth and dislocation recovery. Cold work promotes both nucleation and growth of carbides. Experimental results of decreasing stress exponent with increased particle density (Table 4) contradict Senior's ideas based on threshold stress caused by an irrecoverable dislocation network pinned by fine

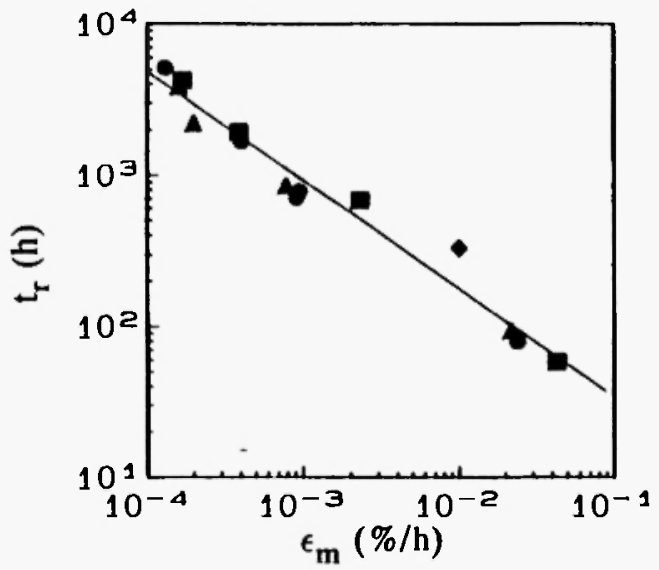

Fig. 7: Monkman-Grant relation: symbols represent

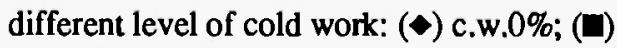
c.w.5\%; (ム) c.w.10\%; (๑) c.w.15\%.

Table 3

$\mathrm{NbC}$ particle sizes $(\mathrm{nm})$ in specimens crept at $650{ }^{\circ} \mathrm{C}$ under various stresses after different cold work

\begin{tabular}{|c|c|c|c|}
\hline $\begin{array}{c}\text { c.w. } \\
\%\end{array}$ & $\begin{array}{c}127 \\
\mathrm{MPa}\end{array}$ & $\begin{array}{c}157 \\
\mathrm{MPa}\end{array}$ & $\begin{array}{c}196 \\
\mathrm{MPa}\end{array}$ \\
\hline 0 & - & - & 9.0 \\
\hline 5 & 8.5 & 6.0 & 8.7 \\
\hline 10 & 8.0 & - & 8.5 \\
\hline 15 & 7.0 & 5.5 & - \\
\hline
\end{tabular}

Table 4

NbC particle densities $\left(10^{21} \mathrm{~m}^{-3}\right)$

in specimens crept at $650{ }^{\circ} \mathrm{C}$ and at various stresses after various pre-straining

\begin{tabular}{||c|c|c|c||}
\hline $\begin{array}{c}\text { c.w } \\
\%\end{array}$ & $\begin{array}{c}127 \\
\mathrm{MPa}\end{array}$ & $\begin{array}{c}157 \\
\mathrm{MPa}\end{array}$ & $\begin{array}{c}196 \\
\mathrm{MPa}\end{array}$ \\
\hline 0 & - & - & 2.0 \\
\hline 5 & 1.4 & 1.8 & 2.2 \\
\hline 10 & 1.9 & - & 2.5 \\
\hline 15 & 2.2 & 2.5 & - \\
\hline
\end{tabular}


Spigarelli

particles $/ 13,14 /$. In Fig. 2, it is possible to observe that differences in creep behaviour tend to reduce at lower stresses.

It seems that an optimum amount of cold work exists which results in the most stably pinned dislocation network and the highest creep strength (corresponding to the lowest MCR, Fig. 2). This amount of predeformation is temperature and stress dependent, and $10 \%$ cold work is the optimum one at $650^{\circ} \mathrm{C}$.

\section{Conclusions}

The results of the interpolation of the experimental data and the microstructural study can be summarized as follows:

- Creep characteristics of cold worked AISI 347 are similar to those typical for other stainless steels. The Monkman-Grant equation is valid and not influenced by pre-straining level; creep strength is controlled by creep strain processes, and no important microstructural damage occurs after cold working.

- Cold deformation does not alter significantly creep constants $n$ and $Q$, even if at high stresses (196 and $157 \mathrm{MPa}$ ); the maximum strengthening effect can be observed in $10 \%$ pre-strained specimens; further pre-straining produces an increase in minimum creep rate.

- Difference in creep strength between "stabilized" and cold worked conditions are less important at lower stresses used in industrial applications. The influence of pre-straining on creep strength seems to be non-linear at high stresses.

\section{Acknowledgements}

This research was supported by ENEL-CRTN.

\section{References}

1. Wadsworth, J., Koewn, J. and Woodhead, J.H., Met. Sci., 10, 105-112 (1976).

2. Novak, C.J., Structure and Constitution of
Wrought Austenitic Stainless Steel, in: Handbook of Stainless Steel, 4.47 - 4.48, D. Peckner and I.M. Bemstein (Eds.), McGraw-Hill (1977).

3. Powell, D.J., Pilkington, R. and Miller, D.A., The Effect of Prestrain on the Creep Fatigue Properties of a $20 \% \mathrm{Cr}-25 \mathrm{Ni}-\mathrm{Nb}$ Stabilized Stainless Steel, Proc. of 2nd Int. Conf. on Creep and Fracture of Engineering Materials and Structures, Pineridge Press, Swansea, 989-1001 (1984).

4. Benharoe, Y., D'Angelo, D., Evangelista, E., Mengucci, P. and Rosen, A., Creep and Aging of 347 Stainless Steel, Proc. Conf. on High Temperature Materials for Power Engineering 1990, Kluwer Academic Publisher, 495-503 (1990).

5. Evans, E. and Wilshire, R.W., Creep of Metals and Alloys, The Institute of Metals, London, 197-243 (1986).

6. Maruyama, K. and Oikawa, H., On Physical Bases of the Modified Theta Projection Concept, Proc. 3rd Int. Conf. on Creep and Fracture of Engineering Materials and Structures, The Institute of Metals, London, 815-828 (1987).

7. Loveday, M.S., Dyson, B.F., in: Creep and Fracture on Engineering Materials and Structures, B. Wilshire and R.W. Evans (Eds.), Proc. 4th Conf., The Institute of Metals, London, 941 (1990).

8. Bernard, L., Campo, E. and Quaranta, S., Creep Behaviour of AISI 304 and 316 Stainless Steel and Influence of Cold Working, Proc. Int. Conf. on Physical Behaviour and Nuclear Application of Stainless Steel at Elevated Temperatures, Varese, Italy (1981).

9. Ahn, Y.S., Bothe, K., Gerold, V. and Kempft, B., in: Creep and Fracture of Engineering Materials and Structures, B. Wilshire and R.W. Evans (Eds.), Proc. 4th Int. Conf., The Institute of Metals, London, 941 (1990).

10. Abou Zahara, A. and Schroeder, H., J. Nucl. Mat., 107, 97-103 (1983).

11. Kikuchi, S. and Ilschner, B., Scripta Metall., 20, 159-162 (1986). 
12. Sheperd, C.M. and James, A.W., Strengthening and Embrittlement Mechanisms in Stainless Steels, Proc. 3rd Int. Conf. on Creep and Fracture of Engineering Materials and Structures, The Institute of
Metals, London, 413-424 (1987).

13. Senior, B., Mater. Sci. Eng., A124, 159 (1990).

14. Senior, B., Mater. Sci. Eng., A130, 51 (1990). 